\title{
Chapter 1 \\ Open and Free Access to Education for All
}

\author{
Martin Weller
}

\begin{abstract}
Open education has evolved over time and now has different interpretations. Three main versions of open education are considered, namely open universities, open educational resources (OER) and MOOCs. These all aim to increase access to education, but have different approaches for realising this aim. The open education landscape is explored using a citation analysis method, to reveal that there is little cross-fertilisation between the distinct areas. In order to address this, a conceptual model is proposed, and the result of a global survey used to analyse the manner in which different institutions are exploiting aspects of openness to increase access. The author concludes that the diverse interpretations of open education can be seen as a benefit, if it allows institutions to assemble approaches for increased access that are tailored to their context.
\end{abstract}

Keywords OER $\cdot$ MOOCs $\cdot$ Open University $\cdot$ Distance learning $\cdot$ Open education $\cdot$ Open access

\subsection{Introduction}

In considering open access to education, it is necessary to review different aspects and interpretations of open education, and to then bring these strands together. This involves different approaches and perspectives in open education including open universities, open educational resources (OER), open textbooks and MOOCs. The historical starting point for the current open education movement is a difficult one to pinpoint, as the answer will vary, depending on the interpretation of open education. This highlights that what we mean by open education is not easily defined. It is probably best viewed not as a single entity but rather as a collection of approaches, intersecting principles and ideas. This section will draw out these principles and ideas, by focusing on the roots of open education. I would suggest that there are three key strands that lead to the current set of open education core concepts: open universities, OER and MOOCs.

\footnotetext{
M. Weller (殴

The Open University, Milton Keynes, UK

e-mail: martin.weller@open.ac.uk

(C) The Author(s) 2020

D. Burgos (ed.), Radical Solutions and Open Science, Lecture Notes

in Educational Technology, https://doi.org/10.1007/978-981-15-4276-3_1
} 


\subsubsection{Open Universities}

Open access to education can be dated back to the founding of UNISA in South Africa in 1946, which pioneered a distance education model to open up education to those who could not attend traditional institutions. With the foundation of the open university in the UK (OU) in 1969 this model was expanded, and the open entry aspect made central. Open approaches to education can be traced prior to these two institutions, for example, through public lectures and movements associated with the industrial revolution, such as the Workers Educational Association (WEA) which was founded in 1903 to improve the education of the working class. However, it is the establishment of the OU and its model which was widely emulated worldwide that provides a reasonable starting point for consideration. Originally proposed as a 'wireless university' in 1926, the idea gained support in the early 1960s, and became a Labour Party manifesto commitment in $1966 .{ }^{1}$ It was established in 1969 with the mission statement that it is 'open to people, places, methods and ideas'. The aim of the OU was to open up education to people who were otherwise excluded because they either lacked the qualifications to enter higher education, or their lifestyle and commitments meant they could not commit to full-time education. The university's approach was aimed at removing these barriers.

The need to expand access to higher education to those who could not access the conventional model became something many governments recognised, and the reputation of the OU for high-quality teaching material and a highly valued learning experience made the approach respectable. Tait (2018) notes that this model was replicated globally, with around 60 Open Universities being established, 'with the largest number being found in Asia, followed by the regions of Europe and Africa'. Notably, the model was not adopted in some large countries such as Russia and the US.

Cormier (2013) suggests the following types of open were important in the OU model:

- Open = accessible, 'supported open learning', interactive, dialogue. Accessibility was key.

- Open = equal opportunity, unrestricted by barriers or impediments to education and educational resources.

- Open = transparency, sharing educational aims and objectives with students, disclosing marking schemes and offering exam and tutorial advice.

- Open = open entry, most important, no requirement for entrance qualifications. All that was needed were ambition and the will/motivation to learn.

In this interpretation, open education was part-time, distance, supported and open access. Significantly, there is no particular stress on cost, so financially free access to education is not emphasised in this interpretation. Education was to be paid for by the respective government, and open universities were closely allied to whatever form of widening participation they wished to adopt. The emphasis was often on affordable

\footnotetext{
${ }^{1}$ http://www.open.ac.uk/about/main/the-ou-explained/history-the-ou.
} 
education, but prior to the advent of the internet, the other forms of openness were seen as more significant. It was with the advent of open source software that 'open' and 'free' began to be linked or used synonymously.

\subsubsection{Open Educational Resources (OER)}

In 2001, the OER movement began in earnest when MIT announced its Open CourseWare initiative. MIT's goal was to make all the learning materials used by their 1800 courses available via the internet, where the resources could be used and repurposed as desired by others, without charge. The William and Flora Hewlett Foundation, who funded the MIT project, define OERs as:

teaching, learning, and research resources that reside in the public domain or have been released under an intellectual property license that permits their free use and re-purposing by others. Open educational resources include full courses, course materials, modules, textbooks, streaming videos, tests, software, and any other tools, materials, or techniques used to support access to knowledge (Hewlett Foundation n.d.).

Note that free cost is now a key component, but also central to this definition is the stress on the license that permits free use and repurposing. In order to satisfy the definition, it is not enough to simply be free as in cost, it has to be reusable also. There are other definitions of OERs available (see Creative Commons, 2013a for a comparison of these) but even if they do not explicitly mandate an open license, they all emphasise the right to reuse content.

Lane (2009) notes that openness as interpreted by the OER movement centres around the freedoms offered by the associated open licenses:

- freedom from paying any money to access and use the content for specified purposes,

- freedom to copy and make many more copies,

- freedom to take away and reuse without asking prior permission,

- freedom to make derivative works (but not necessarily freedom to make profits from them).

This list varies from the one above, being focused on content rather than access to the educational system. In this conceptualisation, the OER movement perhaps owed more to the open source community in terms of influence than it did open universities. It grew out of the growth of the internet and digital technology in the mid-1990s, which caused many educators to examine different models of content creation and sharing. The precursor to OER was Learning Objects, which specifically borrowed from software development ideas of object-oriented code, to enhance reuse. But even though it borrowed little from the OU model, open access to education was a key driver for the OER movement.

For example, a JISC review of the various OER programmes in the UK identified five major motivations (McGill, Falconer, Dempster, Littlejohn, \& Beetham, 2013): 
- building reputation of individuals or institutions or communities

- improving efficiency, cost and quality of production

- opening access to knowledge

- enhancing pedagogy and the students' learning experience

- building technological momentum.

As the authors point out, these motivations are not exclusive and often overlap, and one of them explicitly relates to open access. Similarly, the Hewlett Foundation (2013) state five motivations for why they fund the OER field, the last of which again relates to open access:

- radically reduce costs

- deliver greater learning efficiency

- promote continuous improvement of instruction and personalised learning

- encourage translation and localisation of content

- offer equal access to knowledge for all.

This range of motivations is perhaps not surprising. Universities, including open universities, are themselves complex institutions that fulfil a variety of roles, including education, research, centres of innovation (Etzkowitz, Webster, Gebhardt, \& Terra, 2000), public engagement, agents of social change (Brennan, King, \& Lebeau, 2004), curation and preservation of knowledge and the presence of an independent, trusted voice. So, it should not be a surprise that open education should similarly have myriad roles and purposes.

\subsubsection{MOOCs}

The third main strand to explore for open access to education is the MOOC phenomenon. Collins dictionary defines a MOOC as 'a free online course that many people can study'. The nature of delivery and free cost are the main components in this definition. MOOCs had some relation to the OER movement, as early MOOC pioneers such as David Wiley and Stephen Downes had also been influential in the OER movement. However, it was with the deployment of MOOCs by Stanford Professor Sebastian Thrun on an Artificial Intelligence course, which attracted around 100,000 learners and subsequent interest from venture capitalists that MOOCs really came to public attention. The New York Times declared 2012 to be 'the year of the MOOC' (Pappano, 2012) and this had little to do with either of the previous two movements addressed previously. MOOCs were free to access, but they generally did not come adopt an open licence so their content did not boast the freedoms set out above for OER. Learners were largely unsupported, and so MOOCs did not adopt the Supported Open Learning model of the OU, which places an emphasis on the support of part-time tutors.

Several problems began to emerge with MOOCs after the initial enthusiasm, which saw a reining back on some of the ambitions. The key ones were: 
- Low completion rate-with around only $10 \%$ of registered students completing, completion rates have been problematic for MOOCs (Jordan, 2014).

- Learner demographics-most successful MOOC learners were usually already well educated (Christensen et al., 2013), and this finding undermined claims of MOOCs democratising learning.

- Sustainability - as the MOOC production model became industrialised they required high-quality media outputs, and so their costs increased considerably, particularly when staff time, marketing and support were factored in Hollands and Tirthali (2014). Finding sustainable business models that justified this expenditure has proven problematic.

These issues saw a change in tone around MOOCs, with MOOC provider Coursera (2013) announcing that they were going to "explore MOOC-based learning on campus'. This resembles conventional blended learning, or e-learning, but with a new platform. Similarly, Georgia Tech announced they were offering a masters-level MOOC which was not free (costing \$7000), once again conflating online learning with MOOCs, and Thrun's company Udacity 'pivoted' to focus on corporate training.

Once the initial hyperbole had died away, more practical applications of MOOCs began to emerge. Although the demographics and completion rates remain an issue, millions of people gained access to education through them, finding this way of learning enjoyable and useful, often in areas that are very meaningful to individual's lives. For example, Farrow, Ward, Klekociuk, \& Vickers (2017) report on over 11,000 participants in a MOOC on understanding dementia. There are also examples of their use in formal education to expand the curriculum, for example, the Delft University of Technology offers a 'Virtual Exchange Programme' whereby its campus based students can take MOOCs with other accredited providers, and receive credit at Delft (Pickard, 2018). It can also be argued that MOOCs raised the profile of open access to education within conventional universities, particularly in an online format. Even if MOOCs themselves are only open in terms of enrolment, and not in terms of licencing, their presence has created a dialogue around access to education in a digital age.

\subsection{Mapping Open Education}

These three strands all have in common a motivation to increase access to education, often for learners who are otherwise disadvantaged and denied access to traditional higher education for a variety of reasons. However, it tends to be the case that practitioners in each of these areas sees their view of 'open education' as the dominant or even sole form of open education. This has implications for how open approaches to education develop, for instance, Wiley (2013), Wiley and Hilton III (2018) who is concerned with the OER movement, defines open pedagogy as the 'set of teaching and learning practices only possible in the context of the affordances of open educational resources as enabled by the 5Rs' and talks of OER enabled pedagogies. 
This posits open pedagogy as a function of OER, but the concepts and practices associated with open pedagogy have a longer history than OER. Peter and Deimann (2013) highlight open education practices stretching back to the Middle Ages with the founding of universities which 'contained in them the idea of openness, albeit by no means comprehensive. This period highlights 'open' as learner driven, resting on a growing curiosity and increasing awareness of educational opportunities' (p. 9). Any phrasing of open access education that highlights one form of open education, necessarily does so at the expense of another.

There is then a strong tendency to be self-referential in each of the strands mentioned, with little reference to other forms of open education. A preliminary systematic search (Rolfe, 2016) for 'open education' across a number of databases, retrieved over two hundred articles and revealed that there was an initial peak in the period 1970-74, with articles relating to the founding of the OU and similar approaches. The next significant peak in publications is found in 2010-15 as MOOCs, open textbooks and OER gain traction (Fig. 1.1).

Using a citation analysis method, the landscape of research in open education could be constructed (Weller, Jordan, DeVries, \& Rolfe, 2018). This method proceeded by gaining an initial sample of 20 documents on the basis of literature database searches for items which referred specifically the history or definition of openness [('open education', 'open learning', openness) AND (history, definition)]. The references of these articles were then extracted, and the papers which were cited by at least two of the original sample items were then added to the sample to include their references in the next iteration. Although this process could be repeated indefinitely, four iterations were carried out as meaningful clusters had emerged at this point. At this point, the network included 5,217 references from a total of 172 publications. Using the social network analysis tool Gephi, a network of citations could then be

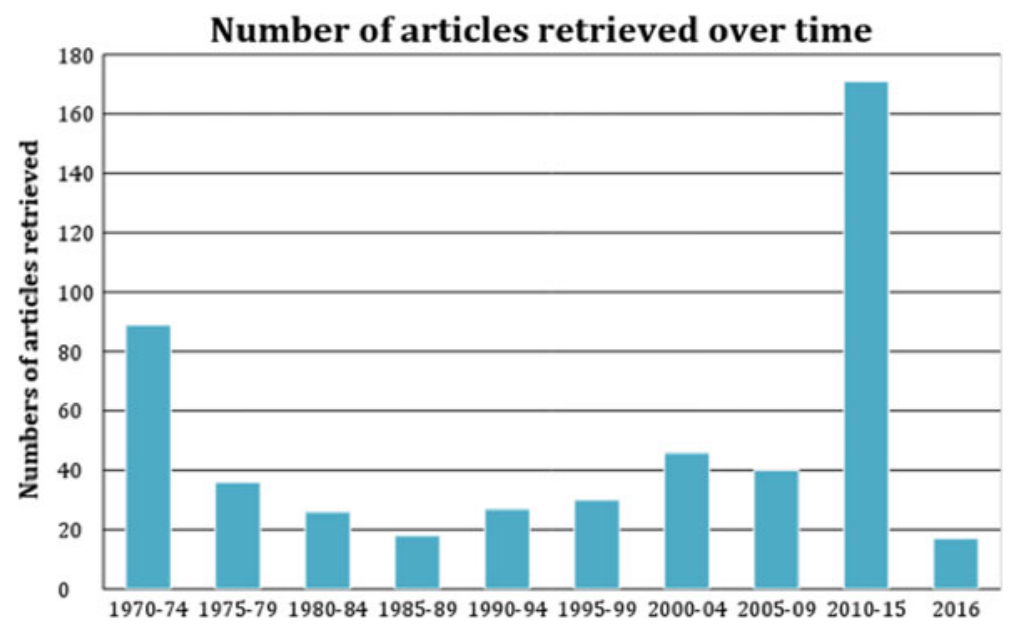

Fig. 1.1 Frequency of published articles on open education over time 


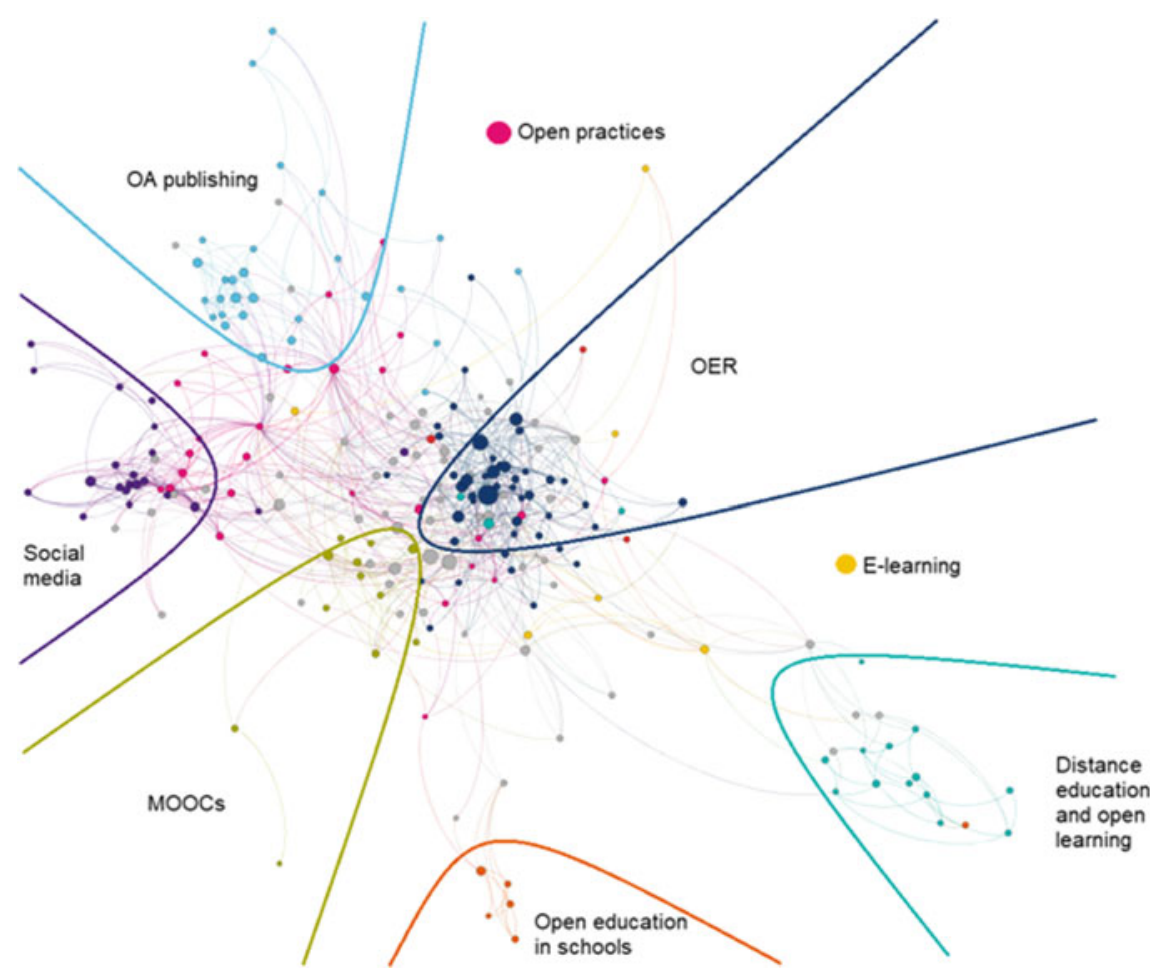

Fig. 1.2 Citation network of open education articles

plotted. Clusters within this could be identified, and appropriate labels imposed. The resulting network is shown in Fig. 1.2.

From this network, eight distinct areas within open education emerged: Distance education, e-learning, open education in schools, OER, MOOCs, Open Access publishing, Social media and open practices. All of these areas have elements of opening up access to educational practice as a core motivation or principle.

What the network demonstrates is that there is indeed little cross-referencing between these areas. Articles on MOOCs, for instance, do not tend to reference ones in OER, and vice versa, and neither reference open and distance education research and so on. In some areas, this might be understandable, for example, many articles on open access publishing are from an information science, librarianship perspective, and similarly the work on social media emerged from a communications focus and evolved into consideration of academic use of such tools. Given the similarity in aims and issues faced by distance education, MOOCs and OERs, the absence of much overlap between them is surprising, however.

Perhaps the area of most interest is that of open practices, or open educational practice (OEP), which acts as a bridge or glue between many of the other clusters, located as it is at the intersection of social media, open access publishing and OER. It 
Table 1.1 The primary drivers for different areas of open education

\begin{tabular}{l|l}
\hline Area of open education & Primary driver \\
\hline Open, distance education & $\begin{array}{l}\text { Removal of barriers to higher } \\
\text { education }\end{array}$ \\
\hline E-learning & $\begin{array}{l}\text { Delivery of education and } \\
\text { support online }\end{array}$ \\
\hline Open education in schools & Physical spaces, inclusion \\
\hline OER & Reuse, access to teaching content \\
\hline MOOCs & Free access to content \\
\hline Social media & Sharing of ideas \\
\hline OA publishing & Reuse, access to research content \\
\hline OEP & Sharing of process and content \\
\hline
\end{tabular}

is, however, also a term that has multiple interpretations, with Cronin and MacLaren (2018) identifying four distinct strands of OEP definition. This generality, or ambiguity, means that it encompasses both the research and teaching remits of higher education, and thus does not form a distinct cluster. In terms of opening access to education, OEP can be viewed then as motivated by both a desire to remove barriers to education, and also to open up the process of education, by sharing data, content and blurring boundaries between academic institutions and the general public.

The eight areas identified in Fig. 1.2 can be summarised as foregrounding different aspects of open access. For example, for open learning, the key component is the removal of barriers to participation in higher education, whereas, for OER, it is the ability to reuse and access content that is of primary importance, while MOOCs highlight the free cost of study. These primary drivers for each of the eight areas are summarised in Table 1.1

What Table 1.1 highlights is that open access to education comes in many different forms, and with differing intentions. No one interpretation is 'correct' but rather their suitability will vary depending on the aims of the institution, educator and learner. However, this multiplicity of definitions, intentions and outcomes can be detrimental to the open movement as it makes the term 'open' so broad as to be meaningless. What is required therefore is a conceptual model to combine these approaches in manner that is meaningful for higher education institutions.

\subsection{A Model for Openness}

Orr, Weller and Farrow (2019) propose such a model, combining open, online, flexible and technology-enhanced (OOFAT) aspects of education. The model needed to provide sufficient structure to provide a meaningful analysis, while being broad enough to capture the range of open approaches we have seen. In order to accomplish this, the conceptual model abstracts higher education to core functions. 
Building on Agarwal (2016) who classifies these functions as: clocks, content and credentials, so higher education can be thought of as comprising how it is delivered ('clocks'), what is delivered ('content') and how achievement is made recognisable to third parties ('credentials'). With a slight reformulation for clarity and conciseness, the basic conceptual model used in this research was based on the following three central processes:

- Content - consisting of subject knowledge, support and guidance and learning analytics, which together make up the entirety of all didactical process.

- Delivery - consisting of the qualities of place, pace and timing of delivery of the content, and format so as to include online, blended and face to face.

- Recognition - consisting of both assessment and credentialisation, which are formal processes leading to recognition of learning achievements. Assessment is a phase of evaluation at certain times in a learning process, while credentials are awarded on completion of formal learning units. In both cases, these evaluative processes entail a formal endorsement of learning and lead to recognition of achievement of the learner by third parties.

With these basic components, the impact of technology to open up the process can then be examined. Two dimensions were used for each of the three core processes, which both speak of new types of openness and flexibility made possible through digitalisation.

- Organisational flexibility: The quality of flexibility is a question of 'what' and 'how' and relies on digital technology to reduce the need for physical presence; from static to dynamic and changing due to specific circumstances. So, each of the three central processes (content, delivery, recognition and their sub-processes) can also be described by the extent to which they are delivered in a flexible manner, harnessing digital technology, that is, through online and technologyenhanced learning environments. This opens up access by reducing the barriers to participation in a strictly face-to-face, time constrained model, as seen with traditional and online open universities.

- Procedural openness: The quality of openness is a 'who' question and relies on how the principle of openness is integrated (in various ways) into the core processes (content, delivery, recognition and their sub-processes); from closed group to more open network. More open processes mean less limitations on who has access to and who delivers or controls content, delivery, assessment and recognition. This opens up access in different ways, for example, by allowing free access to content (as with OER), or more open forms of assessment such as digital badges.

This conceptual model is represented in Fig. 1.3. It comprises the three central processes of higher education provision at its corners and has the two qualities of flexibility and openness.

Using a 5-point Likert scale for how universities perceive themselves on each these dimensions, allows a visual representation, as shown in Fig. 1.4. A global survey of 150 institutions across 36 countries was then conducted to gather their representations 


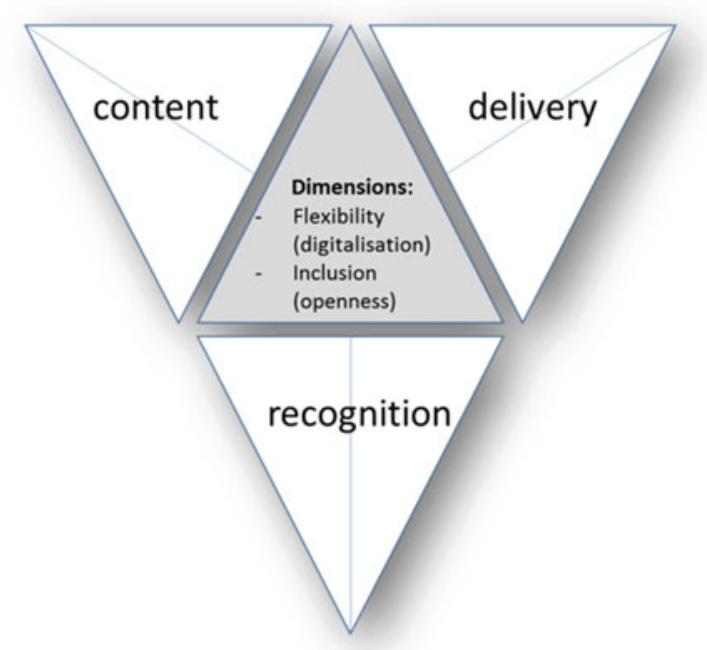

Fig. 1.3 The OOFAT conceptual model

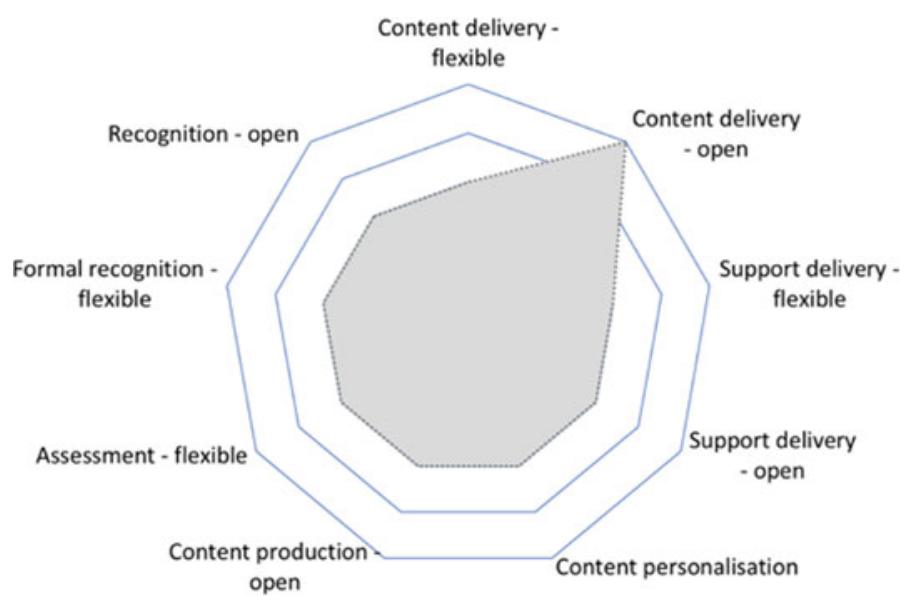

Fig. 1.4 Dimensions of the OOFAT model of Korea National Open University

on this model. Analysis of these different representations reveals some core patterns, which can be then be mapped to approaches to opening up access to education.

Six such patterns emerged from the data:

- OOFAT at the centre

- OOFAT for organisational flexibility

- OOFAT for a specific purpose 
- Content-focused OOFAT model

- Access-focused OOFAT model

- OOFAT for multiple projects

Each of these can be seen as a different, and equally valid, approach to opening access to education. To take each in turn:

OOFAT at the centre-This model can be visualised as a perfect, or near perfect, nonagon (with a scoring of 3 or higher on each dimension), suggesting that OOFAT is not implemented for one specific purpose, or market, but as an integral part of the institution's overall mission. For such institutions, openness is an integral part of every practice, for example, having open enrolment, free access to content, open forms of assessment. An example is the OER University, which is a network of institutions offering free online courses for students worldwide with OERu partners providing accreditation and content. The OERu has a mission statement of 'Towards more affordable education for all students worldwide'. This can be seen as combining both the approach of the traditional open universities and the open license philosophy of the OER movement, and free course approach of MOOCs.

OOFAT for organisational flexibility - many OOFAT visualisations emphasised the flexibility dimension of the three components. An example is the College of the Canyons (COC), which is a public two-year community college in the US. In terms of content, it is currently shifting from in-house content production to decentralised OER content production and reuse. For delivery, students can choose between various schedule formats $(16,12,8$ or 5 week terms, on campus, online, hybrid, etc.). Within these classes, the majority of students can choose time and place of assessments, and enrolment is open entry. This approach uses flexibility to open up access to education.

OOFATfor a specific purpose - regardless of the values given to other dimensions, many providers had at least one clear peak, where flexibility and/or openness was being implemented for a very specific function or market. This may be the result of a particular project or a specific strategy to target one aspect of delivery. For example, the Universitas Terbuka (UT) is Indonesia's 45th state university and employs an open and distance learning system to widen access to higher education to all Indonesian citizens, including those who live in remote islands. Only recently (since 2017), has the university begun to provide digital learning materials and it now gives free internet access via Wi-Fi to students. Opening access here was being focused for a particular audience.

Content-focused OOFAT model-in contrast to the flexibility model which emphasises the flexibility dimension across all aspects of the OOFAT model, other providers concentrate on the component of content specifically. An example is the National Open University of Nigeria (NOUN) which is a federal open and distance learning institution located in Abuja. NOUN encourages its staff to utilise OERs in their lessons and create OER for publication and reuse. With a focus mainly on adult learners, support is also flexible and offered when needed in a traditional distance educational model. This combines aspects then of the traditional open education model and OER to make increase access. 
Access-focused OOFAT model — some providers are utilising digital technologies with the primary intention of increasing access to content or education for specific sets of learners. An example is the Odisha State Open University (OSOU), a distance learning state university located in Sambalpur, Odisha, India. They have a distance education approach, but are particularly exploring the use of other dimensions in terms of improving access. For example, content is free for all but, for certification a nominal fee is charged from eligible learners, adopting some of the MOOC model to increasing access. Faculty and part-time counsellors provide learning support at dedicated study centres. Academic counsellors also evaluate the learners. The system is open and flexible for learners to self-pace their learning path in terms of study time.

OOFAT for multiple projects - lastly, some OOFAT visualisations revealed multiple peaks, which were related to very different initiatives within the institution, suggesting experimentation with different dimensions of higher education provision, before the possible future development of a unified strategy. An example is Thompson Rivers University (TRU) in Kamloops, British Columbia, Canada, which has a large online, open education programme. A highly innovative university, it deploys a wide range of technologies at small scale. For instance, students may choose their own assignments or projects in many instances and frequent use is made of blogging platforms for assessment. Open textbooks are an increasing part of content development. Their delivery is often available without a start date and requires up to 30 weeks to complete.

These all represent different flavours of open education, using technology and a mixture of the three main approaches of MOOCs, open universities and OER to meet the needs of their specific contexts.

\subsection{Discussion and Conclusion}

Open practice has an obvious relationship with higher education. As Wiley and Green (2012) put it, 'Education is, first and foremost, an enterprise of sharing. In fact, sharing is the sole means by which education is effected'. Openness can then be argued to be central to the process of higher education, but through the practical limitations of funding and physical space, a 'closed' model has developed. This has come to be seen as the norm, or a natural state for higher education. The barriers to participation in traditional education are many: cost, time, physical presence, work or family commitments and entry requirements. In addition, cultural factors may conspire to exclude particular groups from participation, including women, certain ethnic groups and students from poorer backgrounds with no family experience of higher education.

Open access to education seeks to explicitly address these barriers and encourage participation in education through a variety of means. The traditional OU approach explicitly targets some of these barriers, as we have seen by the removal of entry requirements, part-time study and distance-based model. OER-based approaches are perhaps more indirect, for example, open textbooks can reduce the cost of textbooks 
for those in formal education (e.g. Wiley, Levi Hilton III, Ellington, \& Hall, 2012), or study of OER provides learners with an opportunity to build up confidence in a subject, leading to participation in formal education (Weller, Jordan, DeVries, $\&$ Rolfe, 2015). MOOCs allow free access to whole courses, but often with the possibility to purchase a certificate of completion. This helps open education to those who may not want to enter formal education, or who already have undergraduate qualifications and seek to update skills or engage in leisure learning.

As the mapping exercise has shown there is little cross-fertilisation between these areas. However, as the work on the OOFAT model illustrates, higher education institutes are themselves combining these three approaches and more in order to realise open access to education. This is often complex, nuanced and tailored to the needs and context of the particular institution. The evolving nature of what constitutes 'open education' has meant that it is now a wide encompassing term, which can be to its detriment. As we have seen with open educational practice, it is a term lacking a clear definition which makes it difficult to identify benefits, or impacts. However, the diversity of opinion as to what constitutes open education can also be framed as a benefit. At the core of each approach is a desire to increase access to some aspect of education. The institutions surveyed in the OOFAT work are viewing these different flavours of openness as something akin to a component box, from which they can select the elements they require and combine these into different configurations which suit their needs.

\section{References}

Agarwal, A. (2016). Where higher education is headed in the 21st century: Unbundling the clock, curriculum and credential. Retrieved from https://blogs.timesofindia.indiatimes.com/toi-editpage/where-higher-education-is-headed-in-the-21st-century-unbundling-the-clock-curriculumand-credential/.

Brennan, J., King, R., \& Lebeau, Y. (2004). The role of universities in the transformation of societies. Centre for Higher Education Research and Information. http://www.open.ac.uk/cheri/documents/ transf-final-report.pdf.

Christensen, G., Steinmetz, A., Alcorn, B., Bennett, A., Woods, D., \& Emanuel, E. (2013). The MOOC phenomenon: Who takes massive open online courses and why? SSRN. http://papers. ssrn.com/sol3/papers.cfm?abstract_id=2350964.

Cormier, D. (2013). What do you mean... open? http://davecormier.com/edblog/2013/04/12/whatdo-you-mean-open/.

Coursera. (2013). 10 US State University systems and public institutions join coursera to explore MOOC-based learning and collaboration on campus. Coursera Blog from http://blog.coursera. org/post/51696469860/10-us-state-university-systems-and-public-institutions.

Creative Commons. (2013a). What is OER? http://wiki.creativecommons.org/What_is_OER\%3F.

Cronin, C., \& MacLaren, I. (2018). Conceptualising OEP: A review of theoretical and empirical literature in Open Educational Practices. Open Praxis, 10(2), 127-143. https://doi.org/10.5944/ openpraxis.10.2.825.

Etzkowitz, H., Webster, A., Gebhardt, C., \& Terra, B. R. C. (2000). The future of the university and the university of the future: Evolution of ivory tower to entrepreneurial paradigm. Research Policy, 29(2), 313-330. 
Farrow, M., Ward, D. D., Klekociuk, S. Z., \& Vickers, J. C. (2017). Building capacity for dementia risk reduction: The preventing dementia MOOC. Alzheimer's \& Dementia: The Journal of the Alzheimer's Association, 13(7), P871-P872.

Hollands, F. M., \& Tirthali, D. (2014). MOOCs: Expectations and reality. Center for Benefit-Cost Studies of Education, Teachers College, Columbia University, 138.

Jordan, K. (2014). Initial trends in enrolment and completion of massive open online courses. The International Review of Research in Open and Distributed Learning, 15(1).

Lane, A. (2009). The impact of openness on bridging educational digital divides. The International Review of Research in Open and Distributed Learning, 10(5).

McGill, L., Falconer, I., Dempster, J.A., Littlejohn, A., \& Beetham, H. (2013). Journeys to open educational practice: UKOER/SCORE review final report. JISC from https://oersynth.pbworks. com/w/page/60338879/HEFCE-OER-Review-Final-Report.

Orr, D., Weller, M., \& Farrow, R. (2019). How is digitalisation affecting the flexibility and openness of higher education provision? Results of a global survey using a new conceptual model. Journal of Interactive Media in Education, 2019(1).

Pappano, L. (2012). The year of the MOOC. New York Times, Nov 2, 2012, from http://www. nytimes.com/2012/11/04/education/edlife/massive-open-online-courses-are-multiplying-at-arapid-pace.html?.

Peter, S., \& Deimann, M. (2013). On the role of openness in education: A historical reconstruction. Open Praxis, 5(1), 7-14. https://doi.org/10.5944/openpraxis.5.1.23).

Pickard, L. (2018). TU Delft students can earn credit for MOOCs from other universities class central. https://www.class-central.com/report/delft-virtual-exchange-program/.

Rolfe, V. (2016). Open, but not for criticism? \#opened16 (p. 2016). USA: Richmond Virginia.

Tait, A. (2018). Open Universities: The next phase. Asian Association of Open Universities Journal, 13(1), 13-23.

Weller, M., de los Arcos, B., Farrow, R., Pitt, B., \& McAndrew, P. (2015). The impact of OER on teaching and learning practice. Open Praxis, 7(4), 351-361.

Weller, M., Jordan, K., DeVries, I., \& Rolfe, V. (2018). Mapping the open education landscape: citation network analysis of historical open and distance education research. Open Praxis, 10(2), $109-126$.

Wiley, D. (2013). What is open pedagogy? https://opencontent.org/blog/archives/2975.

Wiley, D., \& Green, C. (2012). Why openness in education? In D. Oblinger (ed.), Game changers: Education and information technologies, pp. 81-89. Educause.

Wiley, D., \& Hilton III, J. L. (2018). Defining OER-enabled pedagogy. The International Review of Research in Open and Distributed Learning, 19(4). https://doi.org/10.19173/irrodl.v19i4.3601.

Wiley, D., Levi Hilton III, J., Ellington, S., \& Hall, T. (2012). A preliminary examination of the cost savings and learning impacts of using open textbooks in middle and high school science classes. The International Review of Research in Open and Distance Learning, 13(3) http://www.irrodl. org/index.php/irrodl/article/view/1153/2256.

William and Flora Hewlett Foundation. (2013). White paper: Open educational resources—-breaking the lockbox on education. http://www.hewlett.org/library/hewlett-foundation-publication/whitepaper-open-educational-resources. 
Open Access This chapter is licensed under the terms of the Creative Commons Attribution 4.0 International License (http://creativecommons.org/licenses/by/4.0/), which permits use, sharing, adaptation, distribution and reproduction in any medium or format, as long as you give appropriate credit to the original author(s) and the source, provide a link to the Creative Commons license and indicate if changes were made.

The images or other third party material in this chapter are included in the chapter's Creative Commons license, unless indicated otherwise in a credit line to the material. If material is not included in the chapter's Creative Commons license and your intended use is not permitted by statutory regulation or exceeds the permitted use, you will need to obtain permission directly from the copyright holder.

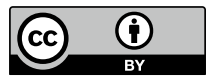

